\title{
Adjoint inversion modeling of Asian dust emission using lidar observations
}

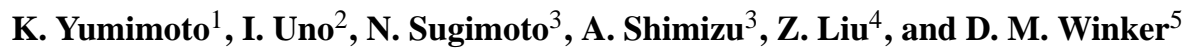 \\ ${ }^{1}$ Department of Earth System Science and Technology, Kyushu University, Fukuoka, Japan \\ ${ }^{2}$ Research Institute for Applied Mechanics, Kyushu University, Fukuoka, Japan \\ ${ }^{3}$ National Institute for Environmental Study, Tsukuba, Japan \\ ${ }^{4}$ National Institute of Aerospace, Hampton, Virginia, USA \\ ${ }^{5}$ NASA Langley Research Center, Hampton, Virginia, USA
}

Received: 12 October 2007 - Published in Atmos. Chem. Phys. Discuss.: 14 November 2007

Revised: 22 April 2008 - Accepted: 13 May 2008 - Published: 5 June 2008

\begin{abstract}
A four-dimensional variational (4D-Var) data assimilation system for a regional dust model (RAMS/CFORS4DVAR; RC4) is applied to an adjoint inversion of a heavy dust event over eastern Asia during 20 March-4 April 2007. The vertical profiles of the dust extinction coefficients derived from NIES Lidar network are directly assimilated, with validation using observation data. Two experiments assess impacts of observation site selection: Experiment A uses five Japanese observation sites located downwind of dust source regions; Experiment B uses these and two other sites near source regions. Assimilation improves the modeled dust extinction coefficients. Experiment A and Experiment B assimilation results are mutually consistent, indicating that observations of Experiment A distributed over Japan can provide comprehensive information related to dust emission inversion. Time series data of dust AOT calculated using modeled and Lidar dust extinction coefficients improve the model results. At Seoul, Matsue, and Toyama, assimilation reduces the root mean square differences of dust AOT by 35-40\%. However, at Beijing and Tsukuba, the RMS differences degrade because of fewer observations during the heavy dust event. Vertical profiles of the dust layer observed by CALIPSO are compared with assimilation results. The dense dust layer was trapped at potential temperatures $(\theta)$ of $280-300 \mathrm{~K}$ and was higher toward the north; the model reproduces those characteristics well. Latitudinal distributions of modeled dust AOT along the CALIPSO orbit paths agree well with those of CALIPSO dust AOT, OMI AI, and MODIS coarse-mode AOT, capturing the latitude at which AOTs and AI have high values. Assimilation results show in-
\end{abstract}

Correspondence to: K. Yumimoto (yumimoto@riam.kyushu-u.ac.jp) creased dust emissions over the Gobi Desert and Mongolia; especially for 29-30 March, emission flux is about 10 times greater. Strong dust uplift fluxes over the Gobi Desert and Mongolia cause the heavy dust event. Total optimized dust emissions are 57.9 Tg (Experiment A; 57.8\% larger than before assimilation) and 56.3 Tg (Experiment B; 53.4\% larger).

\section{Introduction}

Over eastern Asia, soil dust aerosols dominate aerosol loading. They have important effects on the atmospheric environment and climate in the springtime (e.g., Overpeck et al., 1996; Sokolik and Toon, 1996). Numerical simulations are powerful tools to elucidate dust emission, transportation, and deposition. Numerical dust models (e.g., Gong et al., 2003; Liu et al., 2003; Shao et al., 2003; Uno et al., 2004; Tanaka and Chiba, 2005) have been developed for prediction and hindcast analyses. They have provided valuable information related to characteristics of Asian dust phenomena. Nevertheless, proper estimation of dust emissions is quite difficult because of their strong dependence upon various parameters (e.g., soil texture, soil wetness, land-use data, and surface wind speed). Results of the recent dust model intercomparison project (DMIP) (Uno et al., 2006) show that simulated amounts of ten-day dust emission fluxes over eastern Asia among eight dust models differed sometimes by a factor of ten. The wide scattering of dust emissions reflects differences in dust emission schemes, surface boundary data, and meteorological fields within the models. Such uncertainty of estimation of dust emission fluxes strongly influences the model output.

Published by Copernicus Publications on behalf of the European Geosciences Union. 
Four-dimensional variational (4D-Var) data assimilation based on the adjoint model provides insight into various aspects of numerical models (e.g., initial conditions, boundary conditions, and emissions); it has been used for meteorological and oceanographic modeling (e.g., Talagrand and Courtier, 1987; Benjamin et al., 2004; Awaji et al., 2003). Regarding Chemical Transport Models (CTMs), Elbern et al. (1997) and Elbern and Schmidt (1999, 2001) applied 4D-Var data assimilation to the European Air pollution Dispersion model (EURAD), assimilating ozone observations over the European region. Müller and Stavrakou (2005) and Stavrakou and Müller (2006) presented estimates of CO and $\mathrm{NO}_{\mathrm{x}}$ emissions using the IMAGE 4D-Var system with satellite data. Chai et al. $(2006,2007)$ developed a Sulfur Transport Eulerian Model (STEM) 4D-Var System and assimilated a comprehensive observation dataset during experiments for the International Consortium for Atmospheric Research on Transport and Transformation (ICARTT). Hakami et al. (2005) performed an inversion estimate of black-carbon emissions over eastern Asia using the adjoint of the STEM. Yumimoto and Uno (2006) applied 4D-Var to a regional CTM and estimated CO emissions over eastern Asia. Henze et al. (2007) developed the adjoint of GEOS-Chem and validated its feasibility. Dubovik et al. (2008) retrieved global aerosol sources from satellites using an adjoint of the GOCART model. Baker et al. (2006) applied variational data assimilation for $\mathrm{CO}_{2}$. Chevallier et al. (2005) and Meirink et al. (2006) performed inverse modeling from satellite data for $\mathrm{CO}_{2}$ and methane. However, applications of 4D-Var for CTMs remain limited.

For assimilation of dust transport, Niu et al. (2007) developed a dust forecasting system using a three-dimensional variational method (3D-Var). They improved dust concentrations with column observation data observed using the FY-2C satellite (Hu et al., 2007). However, unlike 4D-Var, 3D-Var cannot use observation data of different observation times simultaneously. Yumimoto et al. (2007) developed the 4D-Var data assimilation system of the RAMS/CFORS dust model; using NIES Lidar observations, they estimated dust emissions of a heavy dust event observed on 30 April 2005.

For the present study, we applied RAMS/CFORS-4DVAR (RC4; Yumimoto et al., 2007) to an adjoint inversion of the emission of mineral dust using NIES Lidar network observation data, targeting a dense dust event observed over eastern Asia during late March and early April 2007. We conducted two experiments to evaluate effects of the selection of observation sites on the assimilation results. One experiment used only observation sites located downwind of dust source regions. The other used these sites together with sites near source regions. The assimilation results were validated using various observation data. Surface $\mathrm{PM}_{10}$ concentration, the dust extinction coefficient retrieved from Cloud-Aerosol Lidar with Orthogonal Polarization (CALIOP) onboard CloudAerosol Lidar and Infrared Pathfinder Satellite Observations (CALIPSO), MODerate resolution Imaging Spectroradiome- ter (MODIS; aboard NASA's TERRA and AQUA satellites), Aerosol Optical Thickness (AOT), and the Aura Ozone Monitoring Instrument; Aerosol Index (OMI AI) were used for validation.

This paper is structured as follows. Section 2 describes the RC4 data assimilation system. Section 3 describes the model setup and observation data used in the assimilation. Section 4 presents assimilation results and their validations. Finally, conclusions are summarized in Sect. 5.

\section{Methods}

The RAMS/CFORS-4DVAR (RC4; Yumimoto et al., 2007) consists of a regional dust transport model (RAMS/CFORS; Uno et al., 2003), its adjoint model, and an optimization process. In fact, RAMS/CFORS is built on a mesoscale meteorological model, the Regional Atmospheric Modeling System (RAMS, ver. 4.3; Pielke et al., 1992), using its optional scalar transport system and embedded dust emission, gravitational settling, and dry/wet deposition scheme. Thereby, all meteorological fields from RAMS are used directly for tracer advection and diffusion.

The discrete equation for the mineral dust used in RAMS/CFORS is

$$
\begin{aligned}
\boldsymbol{Q}\left(t_{i+1}\right) & =M\left(\boldsymbol{Q}\left(t_{i}\right)\right)+\boldsymbol{E} d t \\
& =\left\{\mathbf{I}+\left(M_{\mathrm{advc}}+M_{\mathrm{diff}}+M_{\mathrm{reac}}\right) d t\right\} \boldsymbol{Q}\left(t_{i}\right)+\boldsymbol{E} d t,
\end{aligned}
$$

where $\boldsymbol{Q}$ is the dust concentration, $M$ is the model operator, and in which $M_{\text {advc }}, M_{\text {diff }}$, and $M_{\text {reac }}$ respectively represent advection, diffusion, and reaction (including gravitational settling, chemical reaction and conversion, and dry/wet deposition) operators. In addition, $\boldsymbol{E}$ denotes the total dust uplift flux, $t$ is the time, $d t$ is the time step, and $\mathbf{I}$ is a unit matrix.

Strong surface winds uplift mineral aerosols into the atmosphere. The current RC4 calculates the total dust uplift flux based on Uno et al. (2003, 2004), which uses a fourth power-law function of surface friction velocity $u^{*}$, as

$E_{i j, k}=\varepsilon_{i j} C_{i j} f_{k} u_{*}^{3}\left(u_{*}-u_{*, t h}\right), u>u_{*, t h}$,

where $C$ is a dimensional constant that is a function of snow cover, soil wetness and soil texture (Uno et al., 2003); suffix $i j$ denotes grid points. In addition, $u_{*}$ and $u_{*, t h}$ respectively denote surface friction velocity and threshold friction velocity. The RC4 models 12 bin dust particles (radius 0.1$20 \mu \mathrm{m}$ ); $\mathrm{k}$ denotes a bin number. Also, $f$ signifies a fraction of each dust size bin. In this study, we introduce a scaling factor as a control vector to optimize daily dust emissions at each grid and set it equal to unity for the first guess (before assimilation). 
The cost function is redefined as

$$
\begin{aligned}
& J(\boldsymbol{\varepsilon})=\frac{1}{2}\left(\boldsymbol{\varepsilon}-\boldsymbol{\varepsilon}_{\boldsymbol{b}}\right)^{T} \mathbf{B}^{-1}\left(\boldsymbol{\varepsilon}-\boldsymbol{\varepsilon}_{\boldsymbol{b}}\right)+\frac{1}{2} \sum_{i=1}^{n}\left(H_{i} \boldsymbol{\varepsilon}-\boldsymbol{y}\left(t_{i}\right)\right)^{T} \\
& \mathbf{R}^{-1}\left(H_{i} \boldsymbol{\varepsilon}-\boldsymbol{y}\left(t_{i}\right)\right)+\frac{\gamma}{2}\|\Delta(\boldsymbol{\varepsilon}-1)\|^{2}
\end{aligned}
$$

where $\boldsymbol{y}$ denotes an observation, and $H$ represents the forward model operator and the transform operator from the model space into the observation. Furthermore, $\mathbf{B}$ and $\mathbf{R}$ respectively denote the background error covariance and the observation error covariance. The third term is a smoothing term that is used to avoid unrealistic horizontal jumps of the control vector (Carmichael et al., 2008). $\gamma$ is the strength of smoothing. The Laplacian $\left(=\partial^{2} / \partial x^{2}+\partial^{2} / \partial y^{2}\right)$ is $\Delta$.

In fact, RC4 can include the emission scaling factor, initial and boundary dust concentrations, and parameters of removal processes (e.g. dry deposition velocity) in a control vector. The uncertainty of numerical dust modeling includes uncertainties of emission, transport, and removal processes. At first, the uncertainty of transport depends largely on meteorological fields. In the current version of RC4, the meteorological fields were provided by meso-scale model RAMS, which uses NCEP reanalysis data (already assimilated) for initial and boundary conditions, and nudging data. Moreover, DMIP (Uno et al., 2006) reported that the model results correctly captured the major dust onset and cessation timing at surface observation sites; horizontal distributions of surface level dust concentrations appeared quite well in each model. However, the concentration levels were quite different (the difference over the Beijing region became more than 10 times greater). Secondly, Carmichael et al. (2008) estimated that the uncertainty of emission is 2.5 times greater than that of wet removal. On the other hand, as described in Sect. 1, the dust emission flux depends on various parameters; DMIP reported large variance of the emission flux for the eight numerical models. Consequently, we infer that the emission is the most uncertain, and define the emission scaling factor (Eq. 2) as the control vector. To reduce the uncertainty noise of $\boldsymbol{\varepsilon}$, daily dust uplift fluxes are optimized.

Gradients of the cost function (Eq. 2) with respect to a set of the control vectors are necessary to minimize the function. In a 4D-Var system, the adjoint model is used to calculate them. An adjoint of Eq. (1) is derived as follows.

$$
\begin{aligned}
\lambda\left(t_{i}\right) & =\mathbf{M}^{\mathbf{T}} \lambda\left(t_{i+1}\right)+\boldsymbol{\phi}_{i} \\
& =\left\{I+\left(\mathbf{M}_{\mathrm{advc}}^{\mathbf{T}}+\mathbf{M}_{\mathrm{diff}}^{\mathbf{T}}+\mathbf{M}_{\mathrm{reac}}^{\mathbf{T}}\right) d t\right\} \lambda\left(t_{i+1}\right)+\boldsymbol{\phi}_{i}
\end{aligned}
$$

Therein, $\boldsymbol{\lambda}$ represents adjoint variables. Furthermore, $\mathbf{M}_{\mathrm{advc}}^{\mathbf{T}}$, $\mathbf{M}_{\text {diff }}^{\mathbf{T}}$, and $\mathbf{M}_{\text {reac }}^{\mathbf{T}}$ respectively represent adjoint operators of $M_{\text {advc }}, M_{\text {diff, }}$ and $M_{\text {reac }}$. In addition, $\phi$, which shows a discrepancy between simulated and measured values (i.e. residual), drives the adjoint model as a forcing term. In this study, $\boldsymbol{\phi}$ appears as

$\boldsymbol{\phi}_{i}=\mathbf{H}^{T} \mathbf{R}^{-1}\left(H_{i} \boldsymbol{\varepsilon}-\boldsymbol{y}\left(t_{i}\right)\right)$,

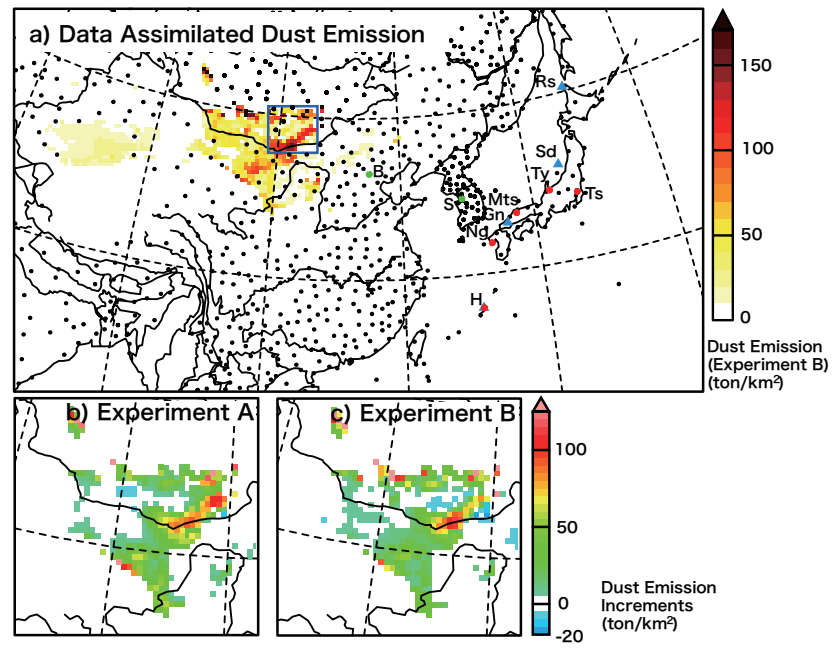

Fig. 1. Model region and NIES Lidar observation sites. (a) Inverted dust emission intensity from 20 March to 3 April (Experiment B). Circles denote NIES Lidar observation sites: Red circles denote NIES Lidar observation sites used in both Experiment A and Experiment B (Tsukuba (Ts), Matsue (Mts), Nagasaki (Ng), and Hedo-Okinawa $(\mathrm{H})$ ). Green circles denote additional Lidar observation sites of Experiment B (Seoul (S) and Beijing (B)). Blue triangles denote PM observation sites. Black circles denote WMO SYNOP observation sites. The blue box indicates a region used to produce averaged emission and wind speed (Fig. 7). (b) Dust emission analysis increment of Experiment A, (c) of Experiment B.

where $\mathbf{H}^{T}$ is an adjoint of $H$ in Eq. (3). The adjoint model is integrated backward in time, and propagates the residual as adjoint variables (also called an influence function), which means that the adjoint model is also useful to perform sensitivity analyses (e.g. Martien et al., 2006).

In $\mathrm{RC} 4$, an iterative optimization routine, which applies Quasi-Newton L-BFGS (Liu and Nocedal, 1989), is used to minimize the cost function. That optimization routine requires several integrations of both forward and adjoint models before a convergence criterion is satisfied. Meteorological fields are generated in advance by RAMS. Pre-calculated RAMS meteorological fields drive the forward and backward models in an off-line manner to reduce computational loads. Consequently, in the current version of RC4, the meteorological fields (e.g., temperature and humidity) have no feedback of the tracer field and were not assimilated. The convergence criterion is that the norm of the gradient of the cost function is reduced by a factor of 1000 with respect to the initial one, meaning that another iteration would produce little difference. In this study, we had around eight iterations.

\section{Experiment setup and observations}

Based on dust extinction coefficients measured by the NIES Lidar observation network, RC4 is applied for assimilation 
Table 1. Observation sites of NIES Lidar and JADS PM measurements: RMS differences between observed and modeled values, with mean values at each site (29 March-4 April).

\begin{tabular}{|c|c|c|c|c|c|c|}
\hline \multirow[t]{2}{*}{ Obs } & \multirow[t]{2}{*}{ Group } & \multirow[t]{2}{*}{ Site } & \multicolumn{2}{|r|}{ RMSD } & \multicolumn{2}{|l|}{ MEAN } \\
\hline & & & & (not assimilated/A/B) & (obs/not assimilated & $\mathrm{A} / \mathrm{B})$ \\
\hline \multirow{7}{*}{ NIES LIDAR $^{\mathrm{a}}$} & $\mathrm{B}$ & Beijing & (B) & $0.15 / 0.35 / 0.22$ & $0.19 / 0.20 / 0.28 / 0.27$ & \\
\hline & B & Seoul & (S) & $0.37 / 0.26 / 0.24$ & $0.34 / 0.14 / 0.33 / 0.32$ & \\
\hline & A, B & Matsue & (Mts) & $0.32 / 0.17 / 0.19$ & $0.27 / 0.087 / 0.23 / 0.22$ & \\
\hline & A, B & Hedo-Okinawa & $(\mathrm{H})$ & $0.074 / 0.060 / 0.061$ & $0.056 / 0.016 / 0.032 / 0.030$ & \\
\hline & A, B & Nagasaki & $(\mathrm{Ng})$ & $0.17 / 0.18 / 0.17$ & $0.14 / 0.065 / 0.14 / 0.13$ & \\
\hline & A, B & Toyama & (Ty) & $0.21 / 0.12 / 0.13$ & $0.17 / 0.056 / 0.15 / 0.14$ & \\
\hline & A, B & Tsukuba & (Ts) & $0.076 / 0.13 / 0.11$ & $0.090 / 0.058 / 0.14 / 0.13$ & \\
\hline \multirow{4}{*}{$\mathrm{JADS} \mathrm{PM}_{10}$} & & Banryu & (Bn) & $163.8 / 150.9 / 148.3$ & $123.2 / 63.9 / 180.4 / 126.9$ & $\left(\mu \mathrm{g} / \mathrm{m}^{3}\right)$ \\
\hline & & Sado & $(\mathrm{Sd})$ & $59.6 / 116.3 / 105.4$ & $50.9 / 50.9 / 132.3 / 93.1$ & $\left(\mu \mathrm{g} / \mathrm{m}^{3}\right)$ \\
\hline & & Hedo-Okinawa & (H) & $53.8 / 57.1 / 74.9$ & $45.6 / 22.3 / 48.9 / 35.4$ & $\left(\mu \mathrm{g} / \mathrm{m}^{3}\right)$ \\
\hline & & Rishiri & (Rs) & $12.1 / 24.0 / 38.1$ & $10.2 / 19.2 / 31.2 / 19.3$ & $\left(\mu \mathrm{g} / \mathrm{m}^{3}\right)$ \\
\hline
\end{tabular}

a RMS differences (RMSD) and mean values are computed based on the dust AOT calculated by integration of the dust ext. coefficients.

of dust observations and inversion of dust emissions over eastern Asia. Figure 1a shows the simulation area, which is centered at $37.5^{\circ} \mathrm{N}, 115^{\circ} \mathrm{E}$ on a rotated polar stereographic system. The horizontal grid comprises $180 \times 100$ grids with $40 \mathrm{~km}$ resolution. The vertical grid comprises 40 grid points extending from the surface to $23 \mathrm{~km}$ with 40 stretching grid layers $(140 \mathrm{~m}$ at the surface to $650 \mathrm{~m}$ at the top) in terrain-following coordinates. Meteorological boundary conditions to RAMS meteorological integration are taken from NCEP/NCAR reanalysis data with $2.5^{\circ} \times 2.5^{\circ}$ resolution and a $6 \mathrm{~h}$ interval. For this study, the simulation is performed during 20 March-4 April 2007 with zero initial dust concentration.

At 14 locations, NIES Lidars (Sugimoto et al., 2006; http://www-lidar.nies.go.jp/) are operating continuously (see Fig. 1a), measuring vertical profiles of dust outflows over eastern Asia with high spatial and temporal resolution. Their vertical and temporal resolutions are, respectively, $30 \mathrm{~m}$ and $15 \mathrm{~min}$. The extinction coefficient is derived based on the backward Fernalds method (Fernald, 1984) by setting a boundary condition at $6 \mathrm{~km}$. We used a non-zero boundary value when the retrieved aerosol profile was negative (Shimizu et al., 2004) setting the Lidar ratio $\mathrm{S} 1=50 \mathrm{sr}$ (Liu et al., 2002). Then the dust extinction coefficient is derived from the extinction coefficient using the contribution of mineral dust, which is estimated using the particle depolarization ratio (Shimizu et al., 2004).

In this study, the vertical profiles of the dust extinction coefficients are assimilated directly. They are used to evaluate the cost function (Eq. 3). Modeled dust extinction coefficients are calculated based on Takemura et al. (2000) at every model time step. We performed two assimilation experiments to evaluate impacts on the assimilation results of the choice of observation sites. Experiment A assimilates five Lidar sites over Japan that are located downstream of the dust source regions. Experiment B assimilates those five sites and another two sites, including sites downstream from and proximate to the dust source region. Consequently, Experiment A includes data of Hedo-Okinawa, Nagasaki, Matsue, Toyama, and Tsukuba. Experiment B uses data of the five sites of Experiment A, with additional data from Beijing and Seoul (Table 1). Observation sites of each set are shown as bold circles in Fig. 1a (red circles represent observation sites used in both Experiment A and Experiment B; green circles represent sites added to Experiment B). The Lidar data are interpolated vertically to the RC4 vertical resolution. Then 1-h averaged Lidar dust extinction coefficients are used for data assimilation with a 3-h interval. For both observation groups, the dust extinction coefficients measured from 29 March to 4 April 2007 from the surface to $4000 \mathrm{~m}$ altitude were assimilated. For this study, surface observations (e.g. $\mathrm{PM}_{10}$ observations) and satellite data (OMI AI, CALIPSO Lidar data, and MODIS aerosol optical thickness) were used only for validation: those data were not applied to data assimilation. The current RC4 can assimilate these observation results. Introduction of these data will be the next step of our application in future studies.

Accurate estimation of the background error (B) of the dust emission flux is important for adequate data assimilation. The dust uplift flux depends on numerous parameters (e.g., soil texture, soil wetness, land-use data, and surface wind speed). In addition, dust emissions over the inland desert region have been measured sparsely. These facts render the estimation of the background error (B) of dust emission extremely difficult. Uno et al. (2006) suggest that dust emission fluxes over eastern Asia differ immensely among the DMIP 8 models. The dust emission fluxes over eastern Asia (including the Gobi desert, Inner Mongolia, and the 

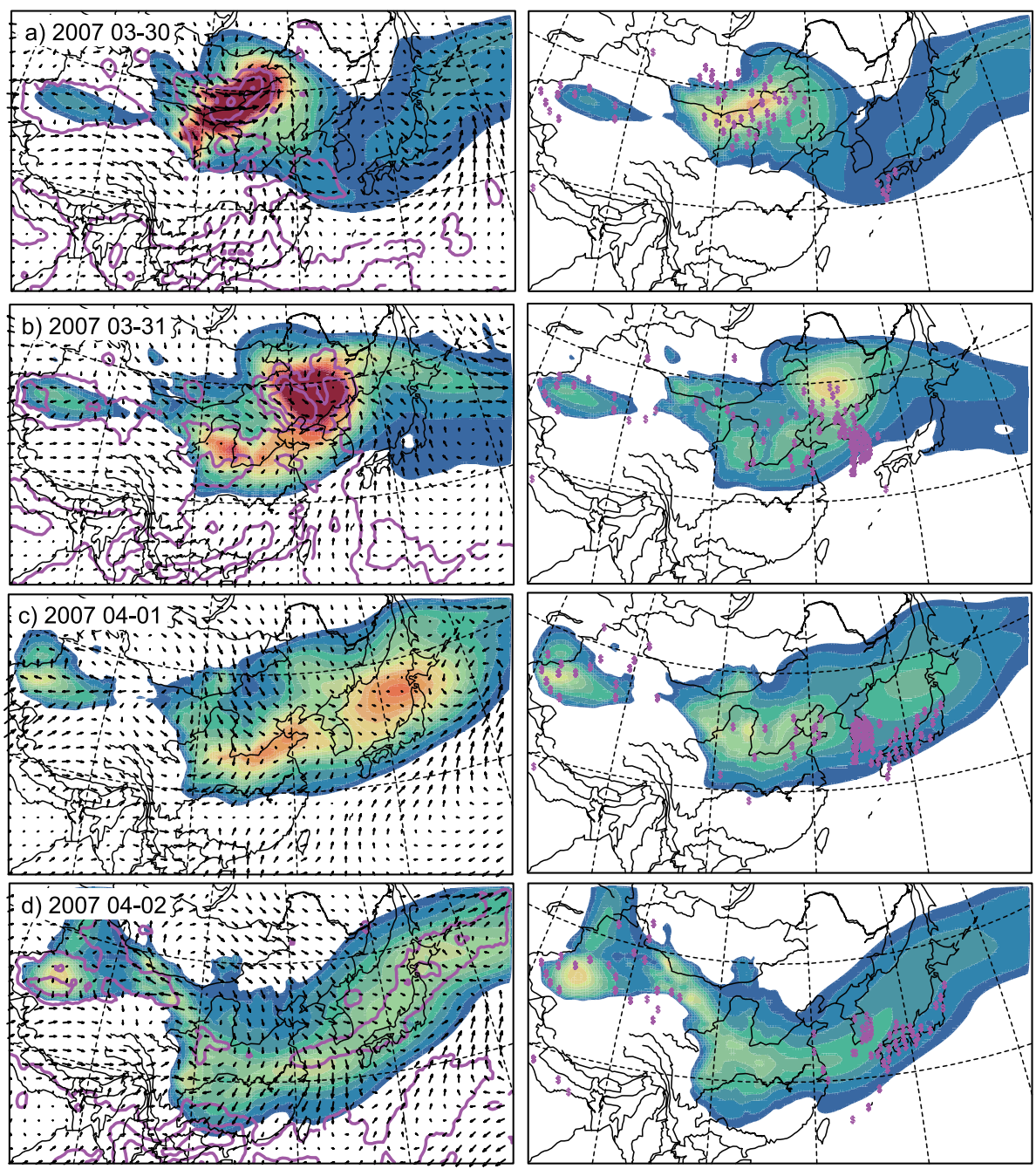

Contour line interval = 1, 3, $5(\mathrm{OMI} \mathrm{Al})$

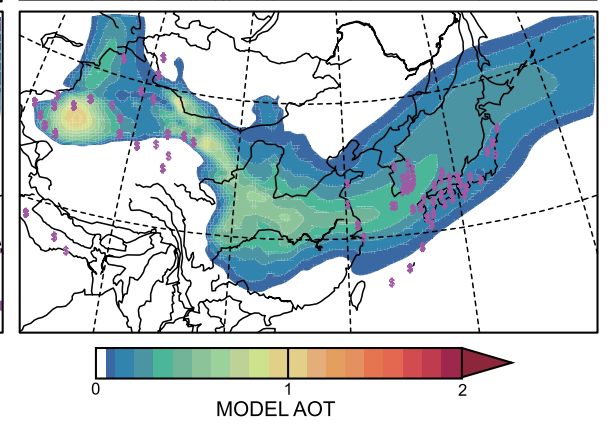

Fig. 2. Comparison of horizontal distributions of modeled AOT and OMI AI: the left column shows modeled dust AOT from assimilation Experiment B (color) and OMI AI (pink lines; interval = 1, 3, 5); the right column shows model dust AOT without assimilation (color) and SYNOP dust report (pink \$ symbols).

Taklimakan Desert) were 27-336 Tg with a mean of $120 \mathrm{Tg}$ for period A (15-25 March 2002), and 18-103 Tg with a mean of $36.3 \mathrm{Tg}$ for period B (4-14 April 2002), reflecting various differences among the models (e.g., dust emission scheme, surface boundary data (e.g., soil texture, soil moisture, and snow cover data), and meteorological fields). The maximum of the dust emission flux of DMIP is sometimes about $600-1200 \%$ of the minimum. In the development stage of our system, we performed several sensitivity experiments changing the uncertainty of the dust flux from $1000 \%$ to $50 \%$. Uncertainty of $500 \%$ engendered reasonable and realistic results that were appropriate for the variations of dust fluxes of DMIP models. In this study, the background error covariance (B) for the dust emission is assumed as diagonal, with assigned uncertainty of $500 \%$ to the dust emission flux as the background error. Measurements near the source region and a detailed evaluation of the background error will help to improve the model prediction and its assimilation.

The observation error covariance $(\mathbf{R})$ is assumed to be diagonal. Sugimoto et al. (2002) estimated the error introduced by the assumption of the Lidar ratio (S1). The extinction coefficient using $\mathrm{S} 1=50 \mathrm{sr}$ was increased by $16 \%$ compared to that using $\mathrm{S} 1=40 \mathrm{sr}$, and decreased by $11 \%$ compared to that using $\mathrm{S} 1=60 \mathrm{sr}$ at $1 \mathrm{~km}$ altitude. Using the relative error alone engenders extremely small observation error and prevents the assimilation procedure from converging on the optimized solution. In this study, we introduced a minimal absolute error and defined the observation errors as

$R_{i i}=\operatorname{Max}\left(R_{\mathrm{abs}}, y_{i} \times R_{\mathrm{rel}}\right)$, 
a) Seoul

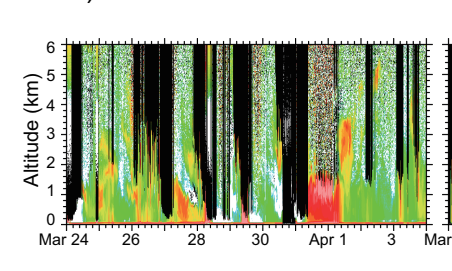

b) Matsue c) Tsukuba
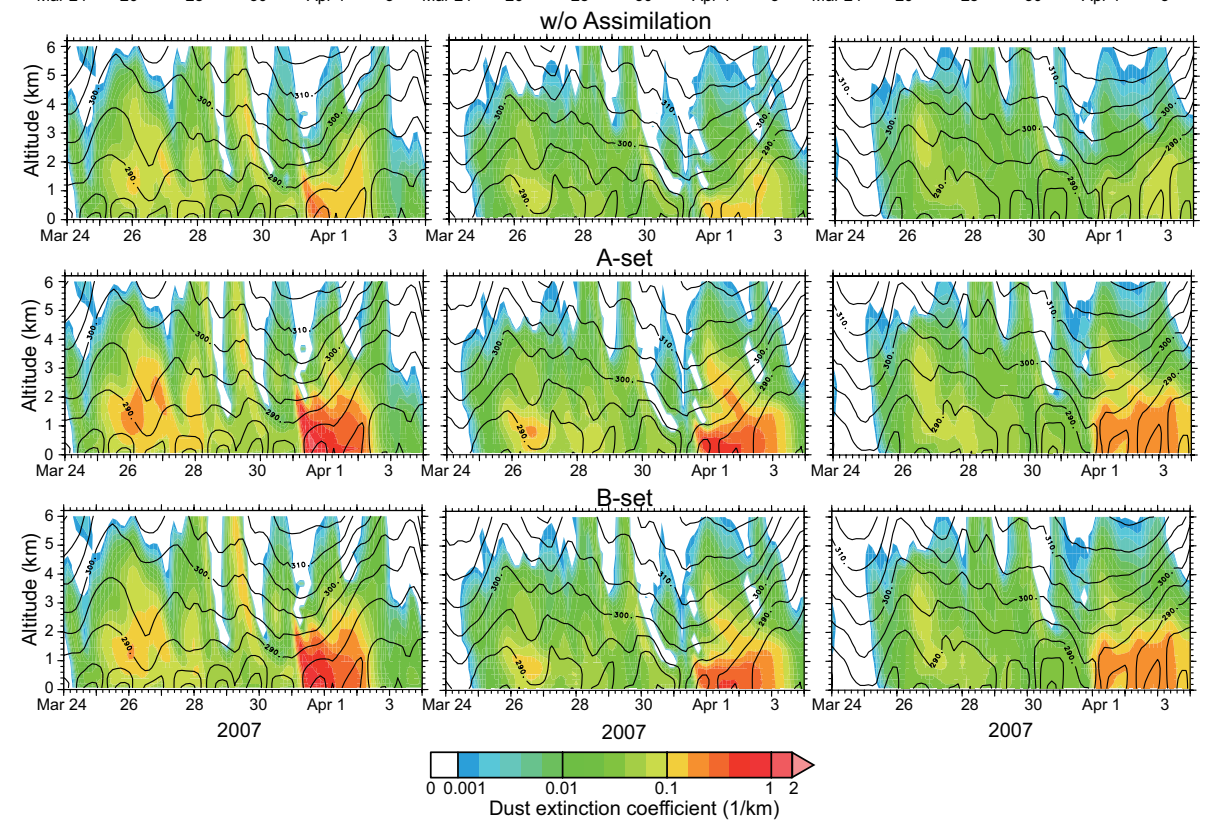

Fig. 3. Time-Height plots of dust extinction coefficients (log-scaled) at Seoul, Matsue, and Tsukuba. The first row shows NIES Lidar observations. Blacked-out areas represent missing data attributable to the presence of clouds, rain, or heavy dense dust layers which the Lidar signal cannot penetrate. Second, third, and fourth rows respectively show modeled dust extinction data without assimilation, assimilated (Experiment A), and assimilated (Experiment B).

where $R_{\text {abs }}$ represents a minimal absolute error set as $0.05 \mathrm{~km}^{-1} ; R_{\text {rel }}$ represents the relative error rate, which was assigned as $10 \%$.

To avoid the unrealistic jumps, using correlation elements of the background error might be useful and physically more meaningful. However, an application of the correlation of the background error matrix will require more sensitivity studies. So we want to keep this sensitivity analysis as a next step of our study. The strength of smoothing $\gamma\left(=10000\left(\mathrm{~m}^{4}\right)\right)$ is decided through sensitivity analyses with another dust event during the develop stage of the system. In this study, final fractions of the background error and the smoothing terms converged on $10 \%$ and $0.5 \%$ of the final value of the cost function (after the convergence), respectively.

In the dust event targeted by this study, the forward dust model (without the assimilation) generally underestimates the dust concentrations (see Figs. 3 and 4), and slightly negative values occurred through the both adjoint inversions. We assumed that the negatives are negligible; they were replaced with zero emissions.

\section{Results and discussion}

\subsection{Assimilation results}

Figure 2 portrays horizontal distributions of modeled AOT and the OMI AI. In the left column, colored and pink contours respectively denote assimilated AOT and OMI AI. In the right column, color represents model dust AOT without assimilation. The symbol \$ shows the dust report from the WMO SYNOP surface weather. Figure 1 shows all SYNOP stations throughout eastern Asia. In fact, OMI AI is also sensitive to non-dust aerosols; high AI levels observed over southern Asia are attributed to aerosols originating from biomass burning (e.g. black carbon). For 1 April, OMI AI data are not available.

A low-pressure area in northeast Mongolia on 30 March created strong surface winds that bore high-density dust aloft over an extended desert region including north-central China and Mongolia. The dust was subsequently transported to the east with the low-pressure system and its accompanying cold front. It reached northeast China on 31 March, extending from the East China Sea to the Sea of Japan on 1 April. It 
covered the islands of Japan on 2 April. The modeled AOT coincides well with OMI AI and SYNOP dust reports. Generally, the modeled AOT is increased by assimilation. The assimilation results reproduce dense dust loadings centered near $105^{\circ} \mathrm{E}$ and $40^{\circ} \mathrm{N}$ on 30 March and covering Japan on 1 April, which was not reproducible using the simple CFORS model.

Figure 3 shows comparisons of observed and modeled dust extinction coefficients at Seoul, Matsue, and Tsukuba. The first and second rows respectively show observations and model results without assimilation. Blacked-out areas in observations show missing observations. Contour lines represent the potential temperature by RAMS. A heavy dust event occurred from 31 March to 1 April at Seoul (dust extinction coefficients were greater than $2 \mathrm{~km}^{-1}$ ), and from 1 April to 2 April at Matsue and Tsukuba. Figure 2 shows that dense dust loading occurred; the dust was trapped by the low-pressure system and its accompanying cold front, which approached Mongolia and north-central China on 30 March 2007, then continued eastward. The dust events observed at each Lidar site are presumed to have detected dust transported by this low-pressure system and its associated cold front. Other observation sites throughout Japan detected a similarly dense dust layer, which arrived between 1 and 2 April with a dense dust extinction coefficient level $\left(>1 \mathrm{~km}^{-1}\right)$. Model results without assimilation represent the onset and overall behavior of the dust layer, but the dust extinction coefficients are underpredicted considerably during the heavy dust event.

The lower two rows in Fig. 3 show assimilation results. The third row shows the results of Experiment A; the fourth row shows results of Experiment B. The assimilation results compensate model dust extinction coefficients considerably and bring modeled concentrations closer to observed ones. At the Tsukuba observation site, two dust peaks observed on 1 and 2 April are reproduced and emphasized by the assimilation. The structures and onset timings of the dust layers are not modified dramatically. The forward model itself precisely represents dust emission timings and source regions. Consequently, the assimilation need not adjust those considerably, but it improves the emission intensity.

At Seoul (Fig. 3a), dense dust layers were observed on 31 March and 1 April. The Lidar was not able to measure dust at altitudes greater than $2000 \mathrm{~m}$ at Seoul between 31 March and early 1 April because the signal was not able to penetrate the very dense dust below that altitude. This fact indicates that dust loading observed at $2000-3500 \mathrm{~m}$ height on 1 April is continuous (not separated) with the dense dust layer on 31 March. The model reproduces the dust layers, including dense dust in upper layers between $2000-3500 \mathrm{~m}$ on 1 April.

At the Matsue observation site (Fig. 3b), the model captures the dense dust loading that occurred between 31 March and 2 April; considerable improvements of the model dust extinction coefficients are apparent during the dense dust loading through assimilation. However, the assimilation results were incapable of reproducing an elevated dust layer on later 30 March at $3000-4000 \mathrm{~m}$ altitude (a similar dust layer is observed at Nagasaki; not shown). The HYSPLIT trajectory model (Draxler and Hess, 1998; http://www.arl. noaa.gov/ready/hysplit4.html) suggests that the air masses corresponding to the dust layers originated above the Taklimakan Desert region (not shown). That region, located in western China, is surrounded by high mountains: the Tian Shan Mountains, Pamir Plateau, Tibetan Plateau, and Kunlun Mountains. Because of its complicated and sharp terrain, it is difficult to reproduce detailed meteorological fields (especially, wind speed and direction, and the boundary layer height; Uno et al., 2005). The resolution of the current RC4 $(40 \mathrm{~km})$ might not be sufficient to reproduce the dust emission and uplifting of the dust particles resulting from the topography conditions (i.e., surface winds, updraft along the sharp terrain, and convection). The difficulty of meteorological simulation prevented assimilation from modifying the dust emission over this region because the adjoint model cannot propagate the required dust emission information (i.e. the residual) to the control vector $\epsilon$ in Eq. (2) backward in time. Improvement of RAMS horizontal resolution might improve the assimilation performance.

Little difference is apparent between results of Experiment A and Experiment B. The Seoul observation site data are not used in Experiment A. Nevertheless, the Experiment A assimilation results improve the model dust extinction coefficient considerably; dramatic improvement is not obtained from Experiment B. Observation sites in Experiment $\mathrm{A}$ are distributed widely over Japan along the meridian, which is perpendicular to the main dust outflow direction. This fact indicates that the observation data of Experiment A captured the dust event characteristics extensively and adequately, and increased the assimilation performance. The existence of only slight differences between results of Experiment $\mathrm{A}$ and Experiment $\mathrm{B}$ also indicate that the assimilated emission by Experiment A is consistent with Lidar-observed results at Seoul and Beijing. The assimilated emissions are discussed in Sect. 4.4. Results of Experiment B are presented as our "assimilation results" in the following sections.

Figure 4 shows time series data of dust aerosol optical thickness (AOT) at Lidar observation sites. The dust AOT is calculated through vertical integration of the dust extinction coefficient from the surface to $6000-\mathrm{m}$ altitude. The total and coarse mode AOTs derived from the aerosol optical depth and the aerosol optical depth ratio provided by the Level-3 MODIS Atmosphere Daily Global Product (Remer et al., 2005) are also shown. It is noteworthy that the MODIS coarse mode AOT is also sensitive to non-dust aerosols (e.g. sea salt).

On 31 March, a dense dust loading was observed at Seoul. This dust loading is presumed to have reached the Beijing site on 30 March. However, weather conditions obscured the observation data. Over the Japanese islands, the dust layer was first observed at Matsue and Toyama on 31 March, then detected at Nagasaki and Tsukuba on 1 April; it finally 

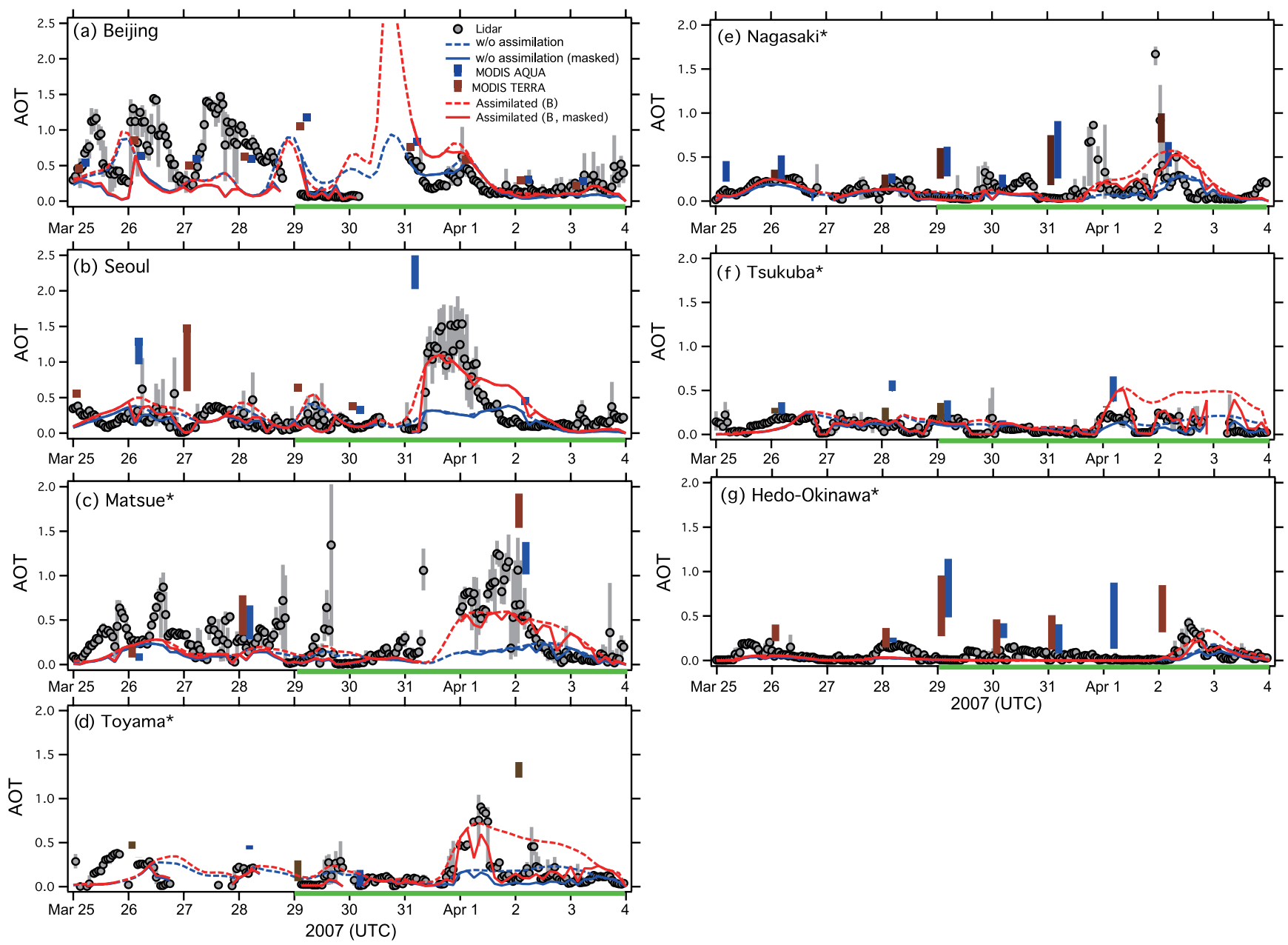

Fig. 4. Time series of Lidar and modeled, MODIS AOT at NIES Lidar sites. Circles denote the 1-h-average of dust AOT calculated using Lidar observations. Gray bars denote ranges between minimum and maximum of Lidar dust AOT. Red lines show assimilated dust AOTs; blue lines are those without assimilation. Dashed lines denote modeled AOTs by the full integral from the surface to $6 \mathrm{~km}$ height. Solid lines denote modeled dust AOTs calculated by the partial integrals, which is only taken over the height range in which Lidar observations are presented. Blue and orange box bars denote ranges between total AOT (box top) and coarse mode AOT (box bottom), as measured by MODIS. Observation data measured during 29 March-4 April are assimilated (shown as green horizontal lines).

reached Hedo-Okinawa on 2 April. The MODIS observations also measured heavy dust loading at each observation site. The model well reproduced those onsets of dust loading.

The assimilation results improve the modeled dust AOT and agree quite well with Lidar dust AOT. Time variations between Lidar AOT and MODIS AOT show good agreement; the assimilation results also capture these variations well. The assimilated dust AOT is increased by $2-2.5$ times compared to that before the assimilation during the dust event, which hit Beijing on 30 March, Seoul between 31 March and 1 April, and Japanese sites on 12 April.

At the Beijing observation site, because of cloudy and rainy conditions that persisted from 29 March to early 31 March, the Lidar measured few vertical profiles of the dense dust layer. Between 25 March and 28 March, the simulated dust AOT remained underestimated compared to the Lidar dust AOT. These high Lidar dust AOT levels might reflect local dust storms and local air pollution, which were unable to reach Seoul and Japanese sites. Assimilations including observation data measured during that period might improve such differences. On 31 March, the Nagasaki and Matsue Lidars detected dense dust that the model was unable to reproduce. As described previously, these elevated dust layers might have originated from the Taklimakan Desert region.

Table 1 presents the root mean square (RMS) of differences between the observed and modeled AOT from 29 March to 4 April, as well as the mean AOT values. Data assimilation improved the RMS differences and the biases between observed and modeled mean values. At Seoul, Toyama, and Matsue, the RMS differences are reduced by 29-47\% in Experiment A and 35-40\% in Experiment B. Experiment A shows significant improvement of the RMS 
differences and the mean value of Seoul. At Beijing, Tsukuba, and Nagasaki, the mean AOT values are brought much closer to observed ones. However, the RMS differences are not improved in spite of the assimilation. At Beijing, the relative lack of data available during the heavy dust event might engender that result. At Nagasaki, dust loading from the Taklimakan Desert observed on 31 March might result in the smaller improvement of the RMS difference. At the Tsukuba site, the observation data of the heavy dust event are fewer than those at other observation sites because of high clouds and rain (see Fig. 2c), which might explain the degradation of the RMS difference.

\subsection{Surface measurements}

Validation of the assimilation results by observations that were not used for the assimilation is crucially important. Figure 5 shows comparisons of time series of surface $\mathrm{PM}_{10}$ at Rishiri, Banryu, Sado, and Hedo-Okinawa (shown as blue triangles in Fig. 1a). Hourly $\mathrm{PM}_{10}$ and $\mathrm{PM}_{2.5}$ (at Rishiri only) observations were provided by the Japan Acid Deposition Survey (JADS) of Japans Ministry of the Environment. Dashed lines denote total dust concentrations; solid lines denote dust $\mathrm{PM}_{10}$ concentrations calculated from the eight smaller bins, with $0.13,0.21,0.33,0.52,0.82,1.27,2.01$, and $3.19 \mu \mathrm{m}$ effective radii, respectively.

The heavy dust layer was measured on 31 March at Banryu and Sado; it then reached Hedo-Okinawa and Rishiri. At Rishiri, the peak concentration of the dust layer is much less (ca. $40 \mu \mathrm{g} / \mathrm{m}^{3}$ ) than at the other sites (ca. 300-800 $\mu \mathrm{g} / \mathrm{m}^{3}$ ) because the dust layer is elevated toward the north, as described in the following Sect. 4.4. Two peaks of concentrations are visible at Banryu and Sado, which are also observed at the Tsukuba Lidar site (see Fig. 3c). The model reproduces these peaks.

Considerable improvements are apparent in $\mathrm{PM}_{10}$ peak concentrations despite the assimilation using only Lidar observations. The modeled peak concentrations are doubled or tripled by the assimilation, and show good agreement with observations. At Hedo-Okinawa, the assimilation results induce the onset time of model $\mathrm{PM}_{10}$ peak to come $3 \mathrm{~h}$ earlier and occur closer to the observed onset time. In contrast, the assimilated $\mathrm{PM}_{10}$ slightly overestimates the observed one at Rishiri. In this study, Experiment A and Experiment B did not include a Lidar observation site located in the north region, that at Sapporo (Fig. 1). Because of rain and clouds, the Sapporo Lidar obtained little observation data during the dust event. Further improvements, especially over the north region, can be expected if such measurements are used for assimilation.

Table 1 also shows the RMS differences and mean values of $\mathrm{PM}_{10}$ concentrations. At Banryu, the assimilations improve the RMS difference and bring the modeled mean concentration closer to the observed one. However, at the other station, the RMS differences are degraded. In Fig. 5, the

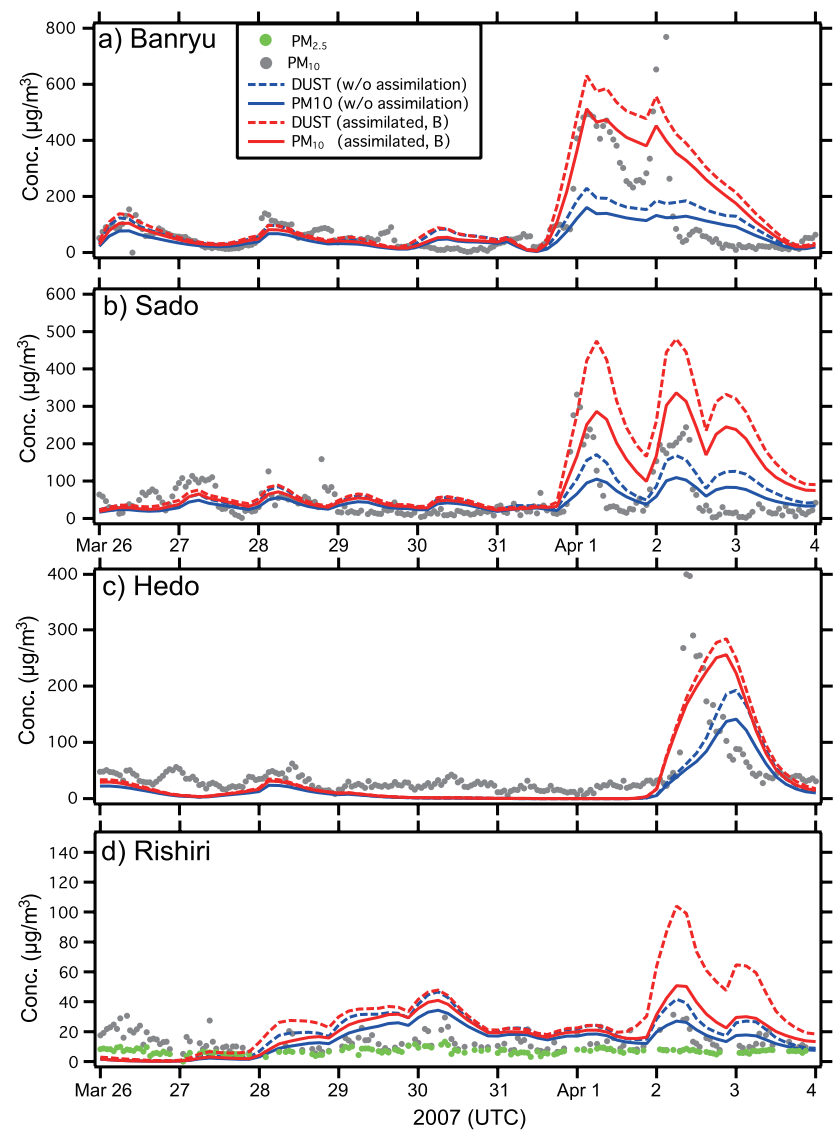

Fig. 5. Comparison of modeled (without assimilation and assimilated) and observed surface $\mathrm{PM}_{10}$ concentrations at Rishiri, Banryu, Sado, and Hedo-Okinawa. Circles show hourly $\mathrm{PM}_{10}$ and $\mathrm{PM}_{2.5}$ (at Rishiri only) observations. Dashed lines denote modeled dust concentrations; solid lines show modeled dust $\mathrm{PM}_{10}$ concentrations calculated with eight smaller bins.

observations show a very rapid decrease of $\mathrm{PM}_{10}$ concentrations at offsets of the dust event. Although the peak $\mathrm{PM}_{10}$ concentrations are improved, the assimilations also engender overestimation of the concentrations after the peak. Degrading of the RMS differences caused by this overestimation after the peak overcomes improvement of RMS differences through better agreement of the peak $\mathrm{PM}_{10}$, resulting in the total degradation of the RMS differences. The model resolution might be insufficient to reproduce the observed sharp peaks. Because of the smaller emission amount, Experiment B yields better RMS differences than those achieved through Experiment A (Sect. 4.4).

\subsection{Space-based lidar}

A space-based backscatter lidar, CALIOP, was launched onboard CALIPSO on 28 April 2006 (Winker et al., 2007). As an active instrument in space, CALIOP is currently providing continuous global measurements of aerosol and cloud 
vertical distributions. The CALIOP data products are therefore an ideal data source for validating the vertical structure of the assimilated dust event. In this section, we compare the assimilation results to the CALIOP products to evaluate our assimilation system.

In fact, CALIOP provides profiles of the total attenuated backscatter coefficient at $532 \mathrm{~nm}$ and $1064 \mathrm{~nm}$, in addition to the depolarization ratio at $532 \mathrm{~nm}$ in the Level 1B data products at horizontal resolution of $333 \mathrm{~m}$. Both vertical and horizontal resolutions vary for different altitude ranges because of the onboard averaging to reduce the data volume to be downlinked. The CALIOP Level 2 data processing finds features (cloud, aerosol, surface, etc.) in a lidar profile and classifies the features. Currently released in the Level 2 layer products are the layer-averaged attenuated optical properties along with cloud-aerosol discrimination (CAD) results. The CAD score is computed based on the cloud and aerosol probability density functions (PDFs) and is used as an indicator for discrimination between clouds and aerosols for the CALIOP layer (Liu et al., 2004). It ranges between -100 and 100: positive values denote clouds, whereas negative values denote aerosols. The absolute value of the CAD score signifies a confidence level for the classification. Detailed descriptions can be found on the CALIPSO web page (http://www-calipso.larc.nasa.gov/) and references therein.

The extinction retrieval is not released in the current Level 2 data products. Therefore, we retrieved dust extinction coefficients from the CALIOP LEVEL 1B data using the same method as that used for NIES Lidar described earlier. The forward inversion is started from $14 \mathrm{~km}$ height down to the ground surface with $\mathrm{S} 1=30 \mathrm{sr}$. For this study, the dust extinction coefficients derived from the CALIOP measurements are averaged to the horizontal resolution of Level $2(5 \mathrm{~km})$.

Figure 6 shows CALIPSO observations and model results. Each CALIPSO path overpasses near the center of the dense dust layer with a low-pressure area; its cold front is as shown in the first row of Fig. 6. The dense dust layer emitted from north-central China and the Mongolia region moved eastward and reached the Sea of Japan on 1 April. On paths A, B, and C, the model results (second row of Fig. 6) show that the dust layer is elevated to the north along the isentropic surface of $\theta=290-300 \mathrm{~K}$ as it travels eastward. In addition, CALIPSO (third row of Fig. 6) captures that elevated dust layer and agrees well with the model results. On path D (Fig. 6d), CALIPSO observed the dust layer over the Yellow Sea; the model also captured the dust layer.

The CAD scores (fourth row of Fig. 6) characterize the CALIOP layers with high dust extinction coefficients as vague (near-zero values). For dense dust layers, because of their high backscatter coefficient and color ratio (similar to those for optically thin clouds), they generally fall in the overlap/vague region of the aerosol and cloud PDFs; the magnitude of CAD scores for this type of aerosol is generally near zero, as demonstrated by the dust layers (greenish in the CAD scores) between $38^{\circ} \mathrm{N}-46^{\circ} \mathrm{N}$ on path $\mathrm{A}, 34^{\circ} \mathrm{N}-$ $42^{\circ} \mathrm{N}$ on path $\mathrm{B}$, and $38^{\circ} \mathrm{N}-43^{\circ} \mathrm{N}$ on path $\mathrm{C}$ in the fourth row of Fig. 6. In this case, misclassifications can occur. Liu et al. (2004) suggested that misclassification can also happen when the aerosol layer is contaminated by embedded or vertically adjacent clouds. In Fig. 2 and the first row of Fig. 6, we show that the dust plume occurred following the passage of the low-pressure area and its accompanying cold front; CALIOP observed the area adjacent to them on path B (Fig. 6b), and close behind them on path A (Fig. 6a) and path $\mathrm{C}$ (Fig. 6c). Heavy dust loading (AOT $>2$ ) occurs adjacent to the cold front and co-exists with the ice-cloud, which complicates the dust classification. The cloud and aerosol discrimination results currently released in the Level 2 layer products are beta version: they are early release products for users to gain familiarity with data formats and parameters. This data product must be validated. The CAD algorithm is being refined for future data releases.

The fifth row in Fig. 6 presents a comparison of the modeled dust AOT, CALIPSO dust AOT, OMI AI, and MODIS coarse mode AOT interpolated along each orbit path. The modeled and CALIPSO dust AOT are calculated through vertical integration of the dust extinction coefficient from the surface to $14 \mathrm{~km}$. The modeled and MODIS AOTs correspond to the left axis, CALIPSO AOT corresponds to the right inside axis, and OMI AI corresponds to the right axis. On 1 April, OMI AI was unavailable. Satellite observations are available once daily: MODIS TERRA overpasses at 10:30 LT (about 02:00 UTC over eastern Asia), MODIS AQUA crosses at 13:30 LT (about 05:00 UTC over eastern Asia), and OMI overpasses at 13:45 LT (about 05:00 UTC over eastern Asia).

In general, the modeled and observed AOT show good agreement, capturing the latitude at which AOTs and AI have high values. Both MODIS TERRA and AQUA coarse mode AOT, and modeled dust AOT are quantitatively consistent. Some dips are apparent in the observations. For example, in path $\mathrm{A}$, two peaks that are not found in model results are produced by a dip around $40^{\circ} \mathrm{N}$ in CALIPSO dust AOT and OMI AI. This dip is caused by a cloud at $10 \mathrm{~km}$ height (see fourth row). Similar observation dips are visible around $39^{\circ} \mathrm{N}$ and $44^{\circ} \mathrm{N}-48^{\circ} \mathrm{N}$ on path $\mathrm{B}$, and around $40^{\circ} \mathrm{N}$ and $43^{\circ} \mathrm{N}$ on path C. On paths B and D (Fig. $6 \mathrm{~b}$ and d), which cross over the Yellow Sea and near industrial regions of east China, satellite observations measure high AOT and AI (e.g., MODIS and OMI observations around lower latitudes on path B, MODIS TERRA observations on path D). These high values might be partly affected by pollution from the industrial region of east China.

Compared to modeled and MODIS coarse mode AOT, CALIPSO dust AOT is lower. Particularly on paths A, B, and $\mathrm{C}$, the upper dense dust layers (AOT $>2$ ) hampered penetrations of CALIPSO Lidar signals to the lower layers, thereby engendering underestimation of CALIPSO dust AOT. Furthermore, the assigned $\mathrm{S} 1$ value ( $\mathrm{S} 1=30$ for this study) might partly affect the underestimation. 
CALIPSO paths and modeled dust AOT (Experiment Bt)
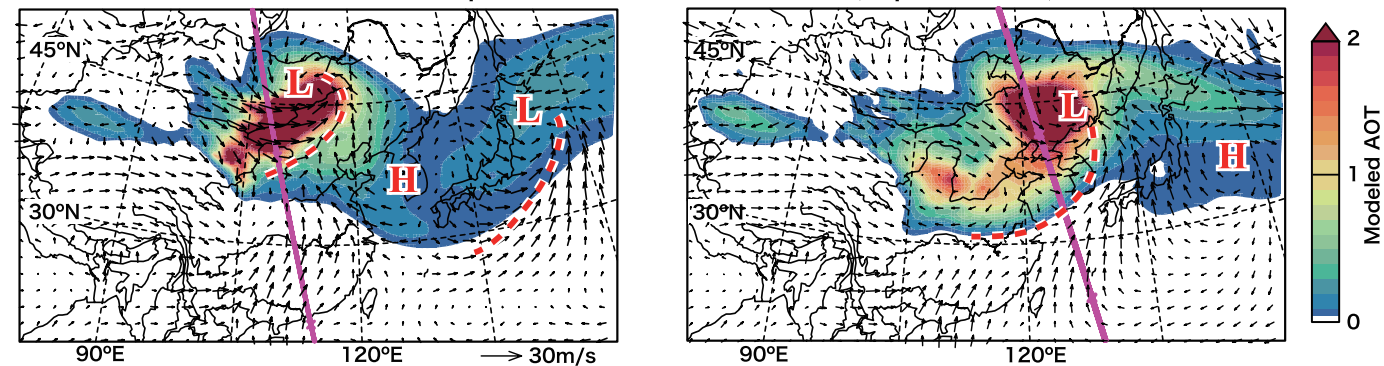

modeled dust extinction coefficient (Experiment B)
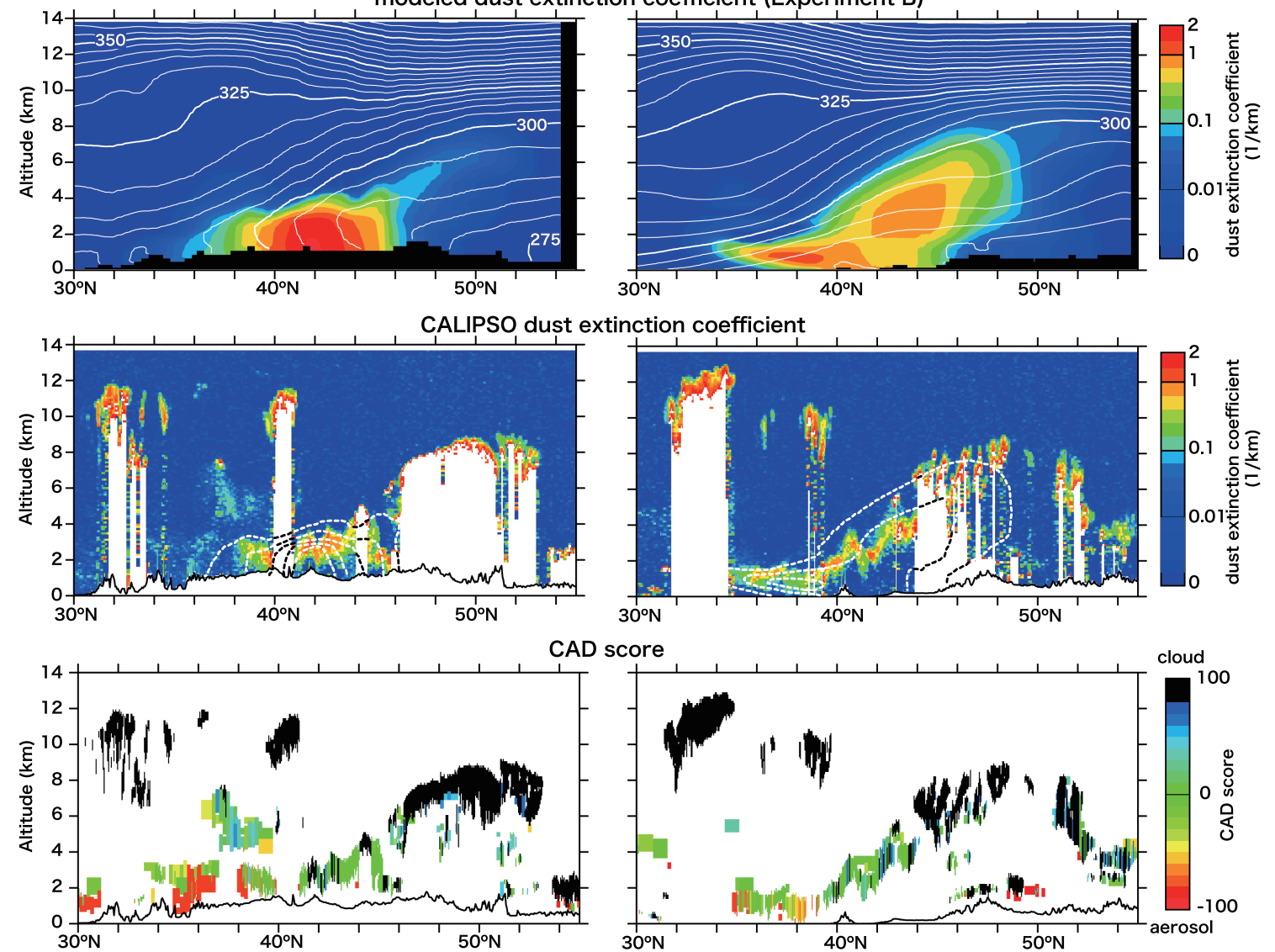

Modeled (Experiment B) and CALIPSO dust AOT, MODIS coarse AOT and OMI AI

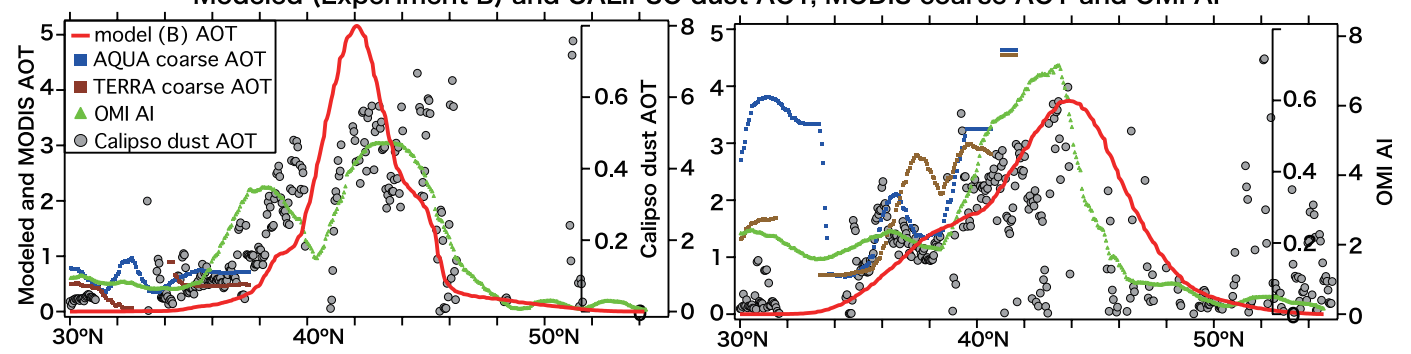

Fig. 6. Comparison of modeled and CALIPSO dust extinction coefficients. The first row shows CALIPSO observation paths and modeled dust AOT (Experiment B) and surface winds. L shows the low-pressure area; red broken lines represent the cold front. The second row shows modeled dust extinction coefficients (color) and potential temperature (white line) along the CALIPSO observation path. The third row shows the CALIPSO dust extinction coefficient (color); broken lines show the modeled dust extinction coefficient $\left(0.5,1.0,1.5,2 \mathrm{~km}^{-1}\right)$. The fourth row shows the CAD score. The fifth row shows the modeled dust AOT (left axis), CALIPSO dust AOT (right inside axis), MODIS coarse AOT (left axis), and OMI AI (right axis) along the CALIPSO path. 
$\begin{array}{ll}\text { c) path C (April } 1 \text { 0357UTC) } & \text { d) path D (April } 1 \text { 1737UTC) }\end{array}$

CALIPSO paths and modeled dust AOT (Experiment B)
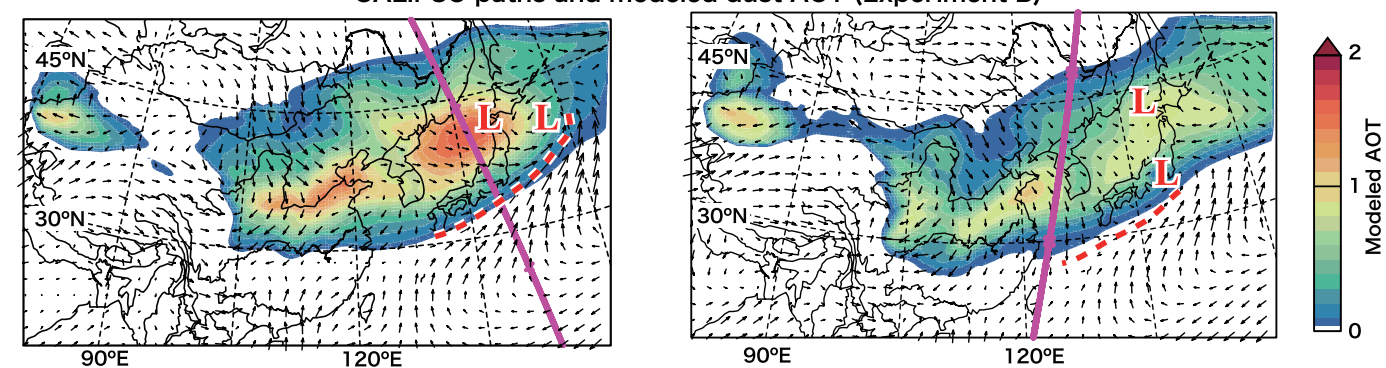

modeled dust extinction coefficient (Experiment B)
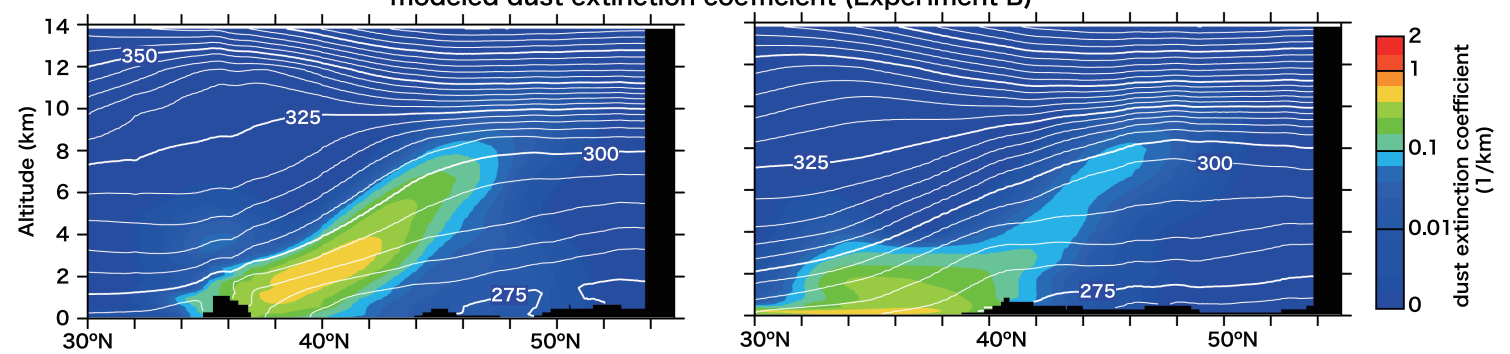

CALIPSO dust extinction coefficient
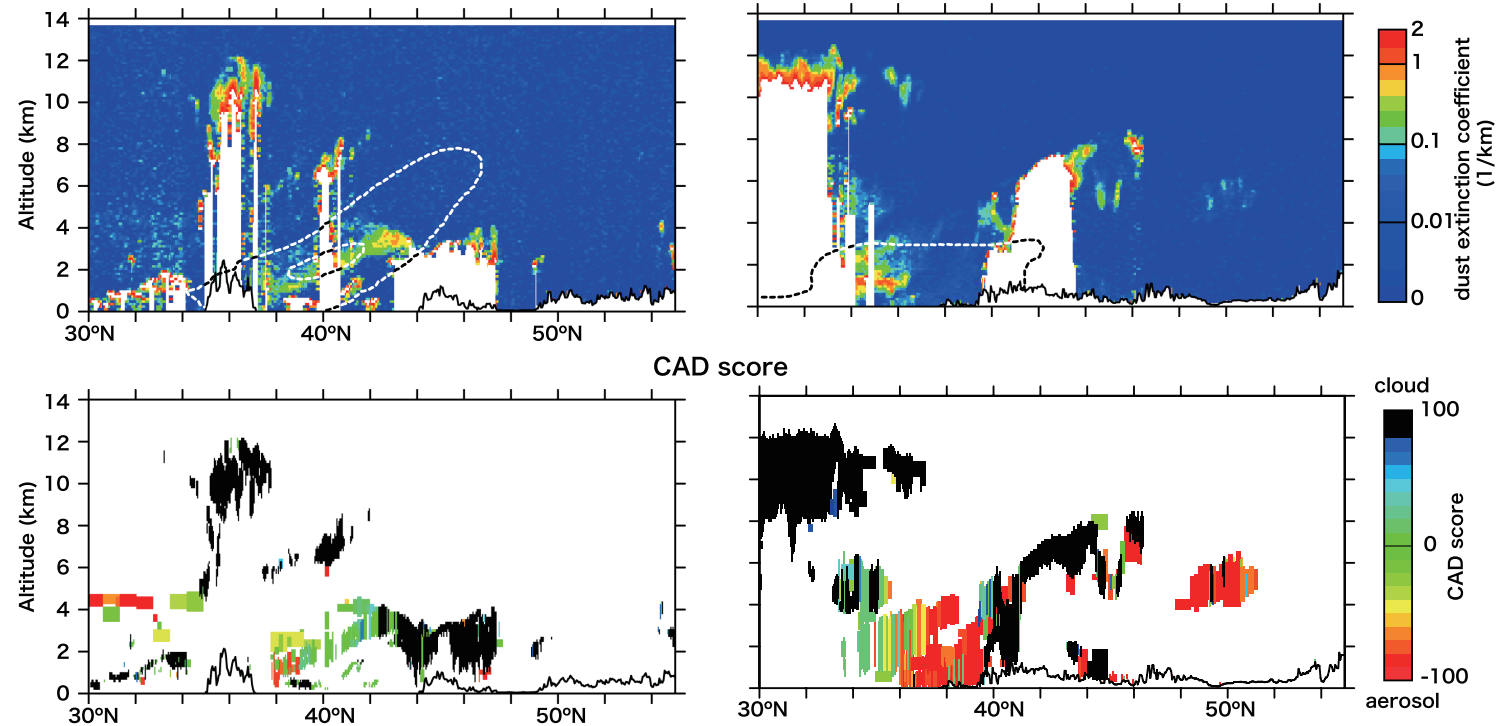

Modeled (Experiment B) and CALIPSO dust AOT, MODIS coarse AOT and OMI AI
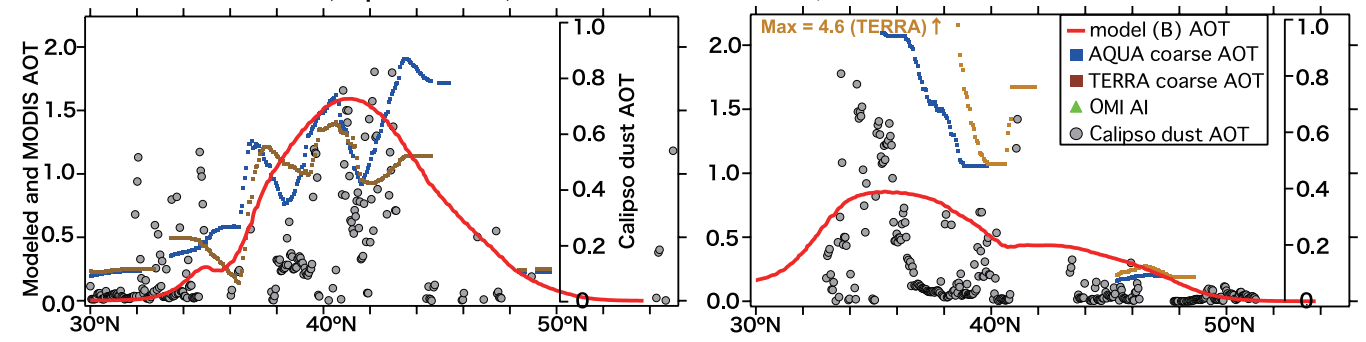

Fig. 6. Continued. 


\subsection{Dust emission}

Figure 1 shows assimilated dust emission intensities from 20 March to 3 April. Figure $1 \mathrm{~b}$ and c respectively depicts increments obtained using results of assimilation for Experiment A and Experiment B. Both results increase dust emissions over the Gobi Desert and Mongolia; especially around the border between China and Mongolia. Despite the close similarity of distributions of increments of dust emission fluxes obtained by Experiment A and Experiment B, some differences exist. These differences might reflect more detailed data related to dust storms observed at Beijing and Seoul, which were not observed over Japan (e.g. a dust storm observed at Beijing on 3 April (see Fig. 4a)). Meanwhile, the close similarity of flux distributions indicates that the assimilation results of Experiment A are consistent with observations made at Beijing and Seoul. Moreover, an assimilation using Experiment A observations can obtain appropriate assimilation results for severe dust storms. As described earlier, the NIES Lidar observation network, which is distributed widely over Japan, enables Experiment A to capture the overall behavior of the dust event. Additionally, observations near the dust storm regions (e.g., Beijing, Seoul, and other new Lidar sites) can include more detailed dust storms in assimilations, and might become crucial for real-time forecasting using a 4D-Var assimilation system.

Figure 7 shows the daily variation of dust fluxes as well as the averaged wind speed, $u_{*}$ and $u_{*, t h}$, in the dust source region (see Fig. 1a). Between 29 and 30 March, the assimilation increases the dust flux considerably. On 29 and 30 March, the model simulated high wind speeds and $u_{*}$. A strong wind blew over Mongolia and north-central China to the northwest; it lifted up enormous amounts of dust particles into the atmosphere. On those days, the assimilation increases dust emission flux by 2-3 times, indicating that the heavy dust storm results from this strong surface wind over those regions on 29 and 30 March. We obtained the total optimized dust emissions of 57.9 Tg (Experiment A, 58\% larger than without the assimilation) and 56.3 Tg (Experiment $\mathrm{B}$, $53 \%$ larger than without the assimilation) during the assimilation window.

Most grid cells in which dust fluxes are increased considerably by the assimilation are designated as having a loamy sand soil texture (not shown). In the current RC4, the initial dust-size distribution of the dust uplift flux is the same in all dust-emission regions. The assimilation results might reflect this poor information about the dust-size distribution. As a future task, optimization of the dust-size distribution at each model grid cell might be necessary. However, few observations provide dust size distributions. Expansion of such observations is both important and necessary.

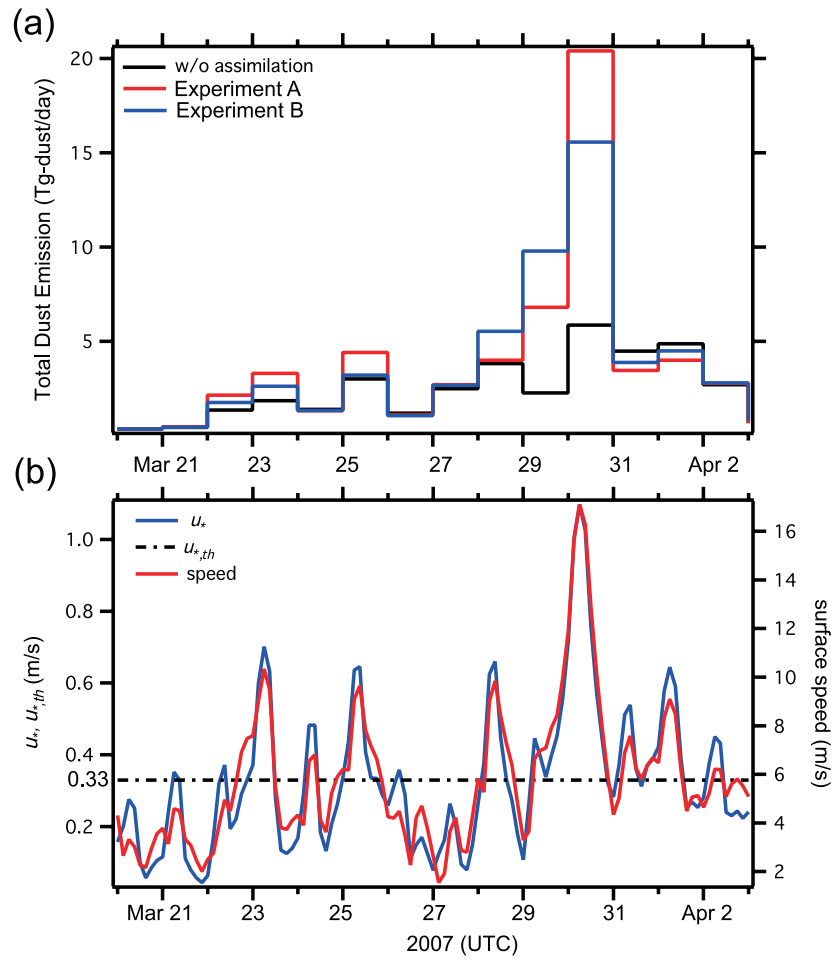

Fig. 7. Daily dust emission flux and regional averaged modeled wind field at lowest model grids and $u_{*}$, and $u_{*, t h}$ throughout the region depicted in Fig. 1a.

\section{Concluding remarks}

Adjoint inverse modeling using the regional dust model was applied to the dust event that occurred over eastern Asia between 20 March and 4 April 2007. The vertical profile of the dust extinction coefficients derived from Lidar observations was assimilated directly. We performed two assimilation experiments to evaluate the impact of observation site selections on assimilation results: Experiment A used five observation sites distributed throughout Japan (downstream of the dust source region); Experiment B used those five observation sites and two other sites nearer the dust source region (Beijing and Seoul). The assimilation results were validated using various observation data: MODIS coarse mode AOT, CALIPSO dust extinction coefficient, OMI AI, the WMO SYNOP weather report, and surface $\mathrm{PM}_{10}$ concentrations. Results can be summarized as follows:

1. Dense dust loading originated from a desert region that extended over north-central China and Mongolia. On 30 March, that region was swept by a low pressure system and its accompanying cold front. The resultant dust, borne aloft, reached the East China Sea and the Sea of Japan on 1 April; it covered the Japanese islands on 2 April. The modeled AOT coincides well with data of these dust onsets and aerosol distributions measured by OMI AI. The assimilation increases the modeled AOT 
and reproduces the dense dust loading, which was not captured before the assimilation.

2. The modeled dust extinction coefficients are improved considerably and come to explain Lidar dust extinction coefficients after assimilation. The assimilation results of Experiment A are consistent with those of Experiment B. This fact indicates that observations of Experiment A can capture the dust layer comprehensively.

3. Time series of dust AOT by the model can capture both Lidar and MODIS coarse mode AOT variations well. Assimilation results increase modeled dust AOT and improve peak dust AOT levels markedly. At Seoul, Toyama, and Matsue, the RMS differences of dust AOT are reduced by $35-40 \%$. However, at Beijing and Tsukuba, the RMS differences degrade because of fewer observations during the heavy dust event. Experiment A also showed improved RMS differences and mean AOT values at Seoul (not included in Experiment A).

4. Surface $\mathrm{PM}_{10}$ concentrations from the Japan Acid Deposition Survey (JADS) are used for independent validation of the assimilation results. The model can generally capture variations of observations and reproduce unique characteristics of two peak $\mathrm{PM}_{10}$ concentrations measured at Banryu and Sado. The assimilation results double or triple the modeled peak concentrations during the heavy dust event and show good agreement with observations. At Banryu, the RMS difference between modeled and observed $\mathrm{PM}_{10}$ is improved. However, at Sado, the RMS differences are degraded, indicating that the model resolution was insufficient to reproduce observed sharp peaks, especially at the end of the dust event.

5. The assimilation results are compared with dust extinction coefficients retrieved by CALIPSO (a satelliteborne Lidar). The model can reproduce observed dust layer characteristics, which are captured between potential temperature $(\theta)$ levels of $285 \mathrm{~K}$ and $295 \mathrm{~K}$, and elevated higher toward the north, quite well. Latitudinal distributions of modeled dust AOT along the CALIPSO orbit paths agree well with the ones of CALIPSO dust AOT, OMI AI, and MODIS coarse mode AOT, capturing the latitude at which AOTs and AI have high values; particularly, modeled dust AOT and the MODIS coarse mode AOT are quantitatively consistent. However, the CALIPSO dust AOT is smaller than either the modeled or MODIS coarse mode AOT. The CALIPSO signal was unable to penetrate to lower layers because of dense upper dust layers (AOT>2), which might cause that underestimation.

6. Assimilation results show considerably increased dust emissions over the Gobi Desert and Mongolia; espe- cially between 29 and 30 March, the dust emission flux increased by $2-3$ times. Dense dust events were caused by the heavy dust uplift flux over the Gobi Desert and Mongolia during those days. We obtained total optimized dust emissions of $57.9 \mathrm{Tg}$ (Experiment A, 57.8\% larger than before assimilation) and 56.3 Tg (Experiment B, 53.4\% larger than before assimilation) during the assimilation window. Distributions of increments of dust fluxes by Experiment A and Experiment B are similar. This similarity indicates that the assimilation results of Experiment A are consistent with observations at Beijing and Seoul. Moreover, observations used in Experiment A can provide appropriate assimilation results because of the wide distribution of the NIES Lidar network.

The NIES Lidar observation sites that are widely distributed throughout islands of Japan captured the dust event extensively and improved the model results. The distribution and location of observation sites strongly affect the performance of data assimilation. The planning of the new observation network can be more effective by intensive integration of observation and numerical model based on data assimilation.

For this study, we used only Lidar network observation data. However, the adjoint inversion can simultaneously include observations obtained from various platforms (e.g., surface and satellite observations). The assimilation of these different data will increase the performance of the adjoint inversion. Nevertheless, biases between the different platforms of observations probably exist. Validations and adequate pre-correction of these mutual biases are necessary for joint assimilation of different observation types: the next step of development of adjoint inversions for dust emissions.

Acknowledgements. This work was partly supported by the Global Environment Research Fund of the Ministry of the Environment, Japan and a Grant-in-Aid for Scientific Research under Grant No. 17360259 from the Ministry of Education, Culture, Sports, Science and Technology, Japan. The authors wish to acknowledge $\mathrm{PM}_{10}$ and $\mathrm{PM}_{2.5}$ data of the Japan Acid Deposition Survey (JADS) used for model validation. CALIPSO data were obtained from the NASA Langley Research Center Atmospheric Sciences Data Center.

Edited by: T. Röckmann

\section{References}

Awaji, T., Masuda, S., Ishikawa, Y., Sugiura, N., Toyoda, T., and Nakajima, T.: State estimation of the North Pacific Ocean by a four-dimensional variational data assimilation experiment, J. Oceanogr., 59, 931-943, 2003.

Baker, D. F., Doney, S. C., and Schimel, D. S.: Variational data assimilation for atmospheric CO2, Tellus, 58B, 359-365, 2006.

Benjamin, S. G., Dévényi, D., Weygandt, S. S., Brundage, K. J., Brown, J. M., Grell, G. A., Kim, D., Schwartz, B. E., Smirnova, 
T. G., and Smith, T. L.: An hourly assimilation-forecast cycle: The RUC, Mon. Weather Rev., 132(2), 495-518, 2004.

Carmichael, G. R., Sandu, A., Chai, T., Daescu, D. N., Constantinescu, E. M., and Tang Y.: Predicting air quality: Improvements through advanced methods to integrate models and measurements, J. Comput. Phys., 227, 7, 3540-3571, 2008.

Chai, T., Carmichael, G. R., Sandu, A., Tang, Y., and Daescu, D. N.: Chemical data assimilation of transport and chemical evolution over the Pacific (TRACE-P) aircraft measurements, J. Geophys. Res., 111, D02301, doi:10.1029/2005JD005883, 2006.

Chai, T., Carmichael, G. R., Tang, Y., Sandu, A., Hardesty, M., Pilewskie, P., Whitlow, S., Browell, E. V., Avery, M. A., Nédélec, P., Merrill, J. T., Thompson, A. M., and Williams, E.: Fourdimensional data assimilation experiments with International Consortium for Atmospheric Research on Transport and Transformation ozone measurement, J. Geophys. Res., 112, D12S15, doi:10.1029/2006JD007763, 2007.

Chevallier, F., Fisher, M., Peylin, P., Serrar, S., Bousquet, P., Breon, F.-M., Chedin, A., and Ciais, P.: Inferring $\mathrm{CO} 2$ sources and sinks from satellite observations: method and application to TOVS data, J. Geophys. Res., 110, D24309, doi:10.1029/2005JD006390, 2005.

Draxler, R. R. and Hess, G. D.: An overview of the HYSPLIT_4 modelling system for trajectories, dispersion, and deposition, Aust. Meteorol. Mag., 47, 295-308, 1998.

Dubovik, O., Lapyonok, T., Kaufman, Y. J., Chin, M., Ginoux, P., Kahn, R. A., and Sinyuk, A.: Retrieving global aerosol sources from satellites using inverse modeling, Atmos. Chem. Phys., 8, 209-250, 2008,

http://www.atmos-chem-phys.net/8/209/2008/.

Elbern, H. and Schmidt, H.: A 4D-Var chemistry data assimilation scheme for Eulerian chemistry transport modeling, J. Geophys. Res., 104(D15), 18 583-18 598, 1999.

Elbern, H. and Schmidt, H.: Ozone episode analysis by fourdimensional variational chemistry data assimilation, J. Geophys. Res., 106(D4), 3569-3590, 2001.

Elbern, H., Schmidt, H., and Ebel, A.: Variational data assimilation for tropospheric chemistry modeling, J. Geophys. Res., 102(D13), 15 967-15 985, 1997.

Elbern, H., Strunk, A., Schmidt, H., and Talagrand, O.: Emission rate and chemical state estimation by 4-dimensional variational inversion, Atmos. Chem. Phys., 7, 3749-3769, 2007,

http://www.atmos-chem-phys.net/7/3749/2007/.

Fernald, F. G.: Analysis of atmospheric LIDAR observations: Some comments, Appl. Opt., 23, 652-653, 1984.

Gong, S. L., Zhang, X. Y., Zhao, T. L., McKendry, I. G., Jaffe, D. A., and Lu, N. M.: Characterization of soil dust aerosol in China and its transport and distribution during 2001 ACE-Asia: 2. Model simulation and validation, J. Geophys. Res., 108(D9), 4262, doi:10.1029/2002JD002633, 2003.

Hakami, A., Henze, D. K., Seinfeld, J. H., Chai, T., Tang, Y., Carmichael, G. R., and Sandu, A.: Adjoint inverse modeling of black carbon during the Asian Pacific Regional Aerosol Characterization Experiment, J. Geophys. Res., 110, D14301, doi:10.1029/2004JD005671, 2005.

Henze, D. K., Hakami, A., and Seinfeld, J. H.: Development of the adjoint of GEOS-Chem, Atmos. Chem. Phys., 7, 2431-2433, 2007 ,

http://www.atmos-chem-phys.net/7/2431/2007/.
Hu, X. Q., Lu, N. M., Niu, T., and Zhang, P.: Operational retrieval of Asian sand and dust storm from FY-2C geostationary meteorological satellite and its application to real time forecast in Asia, Atmos. Chem. Phys., 8, 1649-1659, 2008,

http://www.atmos-chem-phys.net/8/1649/2008/.

Liu, D. C. and Nocedal, J.: On the limited memory BFGS method for large scale optimization, Math. Program., 45, 503-528, 1989.

Liu, Z., Sugimoto, N., and Murayama, T.: Extinction-to-backscatter ratio of Asian dust observed with high-spectral-resolution LIDAR and Raman LIDAR, Appl. Opt., 41, 2760-2767, 2002.

Liu, Z., Vaughan, M. A., Winker, D. M., Hostetler, C. A., Poole L. R., Hlavka, D., Hart, W., and McGill, M.: Use of probability distribution functions for discriminating between cloud and aerosol in lidar backscatter data, J. Geophys. Res., 109, D15202, doi:10.1029/2004JD004732, 2004.

Liu, M., Westphal, D. L., Wang, S., Shimizu, A., Sugimoto, N., Zhou, J., and Chen, Y.: A high-resolution numerical study of the Asian dust storms of April 2001, J. Geophys. Res., 108(D23), 8653, doi:10.1029/2002JD003178, 2003.

Martien, P. T., Harley, R. A., and Cacuci, D. G.: Adjoint sensitivity analysis for a three-dimensional photochemical model: implementation and method comparison, Environ. Sci. Technol., 40(8), 2663-2670, doi:10.1021/es0510257, 2006.

Meirink, J. F., Eskes, H. J., and Goede, A. P. H.: Sensitivity analysis of methane emissions derived from SCIAMACHY observations through inverse modelling, Atmos. Chem. Phys., 6, 1275-1292, 2006,

http://www.atmos-chem-phys.net/6/1275/2006/.

Müller, J.-F. and Stavrakou, T.: Inversion of $\mathrm{CO}$ and $\mathrm{NO}_{\mathrm{x}}$ emissions using the adjoint of the IMAGES model, Atmos. Chem. Phys., 5, 1157-1186, 2005,

http://www.atmos-chem-phys.net/5/1157/2005/.

Niu, T., Gong, S. L., Zhu, G. F., Liu, H. L., Hu, X. Q., Zhou, C. H., and Wang, Y. Q.: Data assimilation of dust aerosol observations for CUACE/Dust forecasting system, Atmos. Chem. Phys. Discuss., 7, 8309-8332, 2007,

http://www.atmos-chem-phys-discuss.net/7/8309/2007/.

Overpeck, J., Rind, D., Lacis, A., and Healy, R.: Possible role of dust-induced regional warming in abrupt climate change during the last glacial period, Nature, 384, 447-449, 1996.

Pielke, R. A., Cotton, W. R., Walko, R. L., Tremback, C. J., Lyons, W. A., Grasso, L. D., Nicholls, M. E., Moran, M. D., Wesley, D. A., Lee, T. J., and Copeland, J. H.: A comprehensive meteorological modeling system-RAMS, Meteorol. Atmos. Phys., 49, 69-91, 1992.

Remer, L. A., Kaufman, Y. J., Mattoo, S., Martins, J. V., Ichoku, C., Levy, R. C., Kleidman, R. G., Tanré, D., Chu, D. A., Li, R.-R., Eck, T. F., Vermote, E., and Holben, B. N.: The MODIS Aerosol Algorithm, Products and Validation, J. Atmos. Sci., 62, 947-973, 2005.

Shao, Y., Yang, Y., Wang, J., Song, Z., Leslie, L. M., Dong, C., Zhang, Z., Lin, Z., Kanai, Y., Yabuki, S., and Chun, Y.: Northeast Asian dust storms: Real-time numerical prediction and validation, J. Geophys. Res., 108(D22), 4691, doi:10.1029/2003JD003667, 2003.

Shimizu, A., Sugimoto, N., Matsui, I., Arao, K., Uno, I., Murayama, T., Kagawa, N., Aoki, K., Uchiyama, A., and Yamazaki, A.: Continuous observations of Asian dust and other aerosols by polarization lidars in China and Japan during ACE-Asia, J. Geo- 
phys. Res., 109, D19S17, doi:10.1029/2002JD003253, 2004.

Sokolik, I. N. and Toon, O. B.: Direct radiative forcing by anthropogenic airborne mineral aerosols, Nature, 381, 681-683, 1996.

Sugimoto, N., Matsui, I., Shimizu, A., Uno, I., Arai, K., Endoh, T., and Nakajima, T.: Observation of dust and anthropogenic aerosol plumes in the Northwest Pacific with a two-wavelength polarization lidar on board the research vessel Mirai, Geophys. Res. Lett., 29(19), 1901, doi:10.1029/2002GL015112, 2002.

Sugimoto, N., Shimizu, A., Matsui, I., Dong, X., Zhou, J., Bai, X., Zhou, J., Lee, C.-H., Yoon, S.-C., Okamoto, H., Uno, I.: NetworkObservations of Asian Dust and Air Pollution Aerosols UsingTwo-Wavelength Polarization Lidars, 23rd International Laser Radar Conference, July 2006 Nara, Japan (23ILRC, ISBN 4-9902916-0-3), 851-854, 2006.

Stavrakou, T. and Müller, J.-F.: Grid-based versus big region approach for inverting $\mathrm{CO}$ emissions using Measurement of Pollution in the Troposphere (MOPITT) data, J. Geophys. Res., 111, D15304, doi:10.1029/2005JD006896, 2006.

Takemura, T., Okamura, H., Maruyama, Y., Numaguti, A., Higurashi, A., and Nakajima, T.: Global three-dimensional simulation of aerosol optimal thickness distribution of various origins, J. Geophys. Res., 105, 17 853-17 873, 2000.

Talagrand, O. and Courtier, P.: Variational assimilation of meteorological observations with the adjoint vorticity equation. I: Theory, Q. J. Roy. Meteor. Soc., 113, 1311-1328, 1987.

Tanaka, T. Y. and Chiba, M.: Global simulation of dust aerosol with a chemical transport model, MASINGAR, J. Meteorol. Soc. Jpn., 83A, 255-278, 2005.
Uno, I., Satake, S., Carmichael, G. R., et al.: Numerical study of Asian dust transport during the springtime of 2001 simulated with the Chemical Weather Forecasting System (CFORS) model, J. Geophys. Res., 109, D19S24, doi:10.1029/2003JD00422, 2004.

Uno, I., Harada, K., Satake, S., Hara, Y., and Wang, Z.: Meteorological Characteristics and Dust Distribution of the Tarim Basin Simulated by the RAMS/CFORS Dust Model, J. Meteorol. Soc. Jpn., 83A, 219-239, 2005.

Uno, I., Wang, Z., Chiba, M., Chun, Y.-S., Gong, S., Hara, Y., Jung, E., Lee, S.-S., Liu, M., Mikami, M., Music, S., Nickovic, S., Satake, S., Shao, Y., Song, Z., Sugimoto, N., Tanaka, T., and Westphal, D.: Dust model intercomparison (DMIP) study over Asia: Overview, J. Geophys. Res., 111, D12213, doi:10.1029/2005JD006575, 2006.

Winker, D. M., Hunt, W. H., and McGill, M. J.: Initial performance assessment of CALIOP, Geophys. Res. Lett., 34, L19803, doi:10.1029/2007GL030135, 2007.

Yumimoto, K. and Uno, I.: Adjoint inverse modeling of CO emissions over the East Asian region using four dimensional variational data assimilation, Atmos. Environ., 40, 6836-6845, 2006.

Yumimoto, K., Uno, I., Sugimoto, N., Shimizu, A., and Satake, S.: Adjoint inverse modeling of dust emission and transport over East Asia, Geophys. Res. Lett., 34, L00806, doi:10.029/2006GL028551, 2007. 